A version of this paper appears in Shieva Kleinschmidt (ed.), Mereology and Location

(Oxford University Press, 2014).

\title{
A SPATIAL APPROACH TO MEREOLOGY
}

\author{
Ned Markosian \\ Western Washington University
}

\section{Introduction}

Recent discussions of the mereology of physical objects have focused mainly on the question of when several objects compose a further object. According to the most popular view on the market, there is a physical object composed of your brain and Jeremy Bentham's body. According to the second-most popular view on the market, there are no such objects as human brains or human bodies, and there are also no atoms, rocks, tables, or stars, either. And according to perhaps the third-ranked view, there are human bodies, but still no brains, atoms, rocks, tables, or stars.

Although it's pleasant to have so many crazy-sounding views around, I think it would also be nice to have a commonsense option available. The aim of this paper is to offer such an option. The approach I want to offer begins by considering a mereological question other than the standard one that has been the focus of most discussions in the literature. I will try to show that the road to mereological sanity begins with giving the most straightforward and commonsensical answer to this other question, and then extending that answer to further questions about the mereology of physical objects. On the approach I will be recommending, it turns out that all of the mereological properties and relations of physical objects are determined by their spatial properties and relations.

Before we get into all of that, here are two important preliminary matters. First, I will be talking in this paper about the mereology of physical objects, but will have little to say about the mereology of non-physical objects. Second, I 
will assume without argument (here) that physical objects are objects with spatial locations. ${ }^{1}$

\section{Mereological Madness}

It's important to be clear about what all the different crazy-sounding views are views about. They are all responses to a question that Peter van Inwagen raises in his book, Material Beings. The question has to do with the notion of composition, which van Inwagen defines as follows.

The $x$ s compose $y=\mathrm{df}$ the $x s$ do not overlap and each one of the $x s$ is a part of $y$ and every part of $y$ overlaps at least one of the $x s .^{2}$

Then van Inwagen's question can be put like this.

The Special Composition Question (SCQ): Under what circumstances do several objects compose a further object? ${ }^{3}$

On one level SCQ is merely asking for necessary and sufficient conditions under which composition occurs. But I think it's clear that what we really want in an answer to SCQ is an account of what it is in virtue of which composition occurs, and also clear that the various answers that have been proposed are meant to give such an account. ${ }^{4}$

The view that I referred to above as the most popular one on the market, according to which there is an object composed of your brain and Jeremy

\footnotetext{
${ }^{1}$ I argue for this account of physical objects in "What Are Physical Objects?"

2 The definition above is a stylistic variant of van Inwagen's definition from Section 2 of Material Beings.

${ }^{3}$ My formulation of SCQ is also a stylistic variant of van Inwagen's (which is also to be found in Section 2 of Material Beings).

${ }^{4}$ It should be noted that most writers on SCQ do not explicitly take the same attitude. For most of them write as if the main project is merely to discover necessary and sufficient conditions for composition. Since my approach is somewhat non-standard in this way, and since my emphasis on trying to discover what it is in virtue of which instances of composition occur plays an important role in some of what follows, it is worth flagging it at the outset. So please place a small flag here.
} 
Bentham's body, is known as Universalism. On this view, any time there is a group of objects, there is a further object composed of the members of that group. Here is a way to state the view.

Universalism: Necessarily, for any $x s$, there is a $y$ composed of those $x s$ iff the $x$ s do not overlap. ${ }^{5}$

(The "do not overlap" part is because of the definition of 'the $x$ s compose $y$ '.) The idea behind Universalism is that any (non-overlapping) $x s$, just in virtue of existing, are such that they compose something. I hope it's clear that this view has many bizarre-sounding consequences, including the one about your brain and Bentham's body. ${ }^{6}$

The second-most popular view on the market, Nihilism, is the opposite extreme of Universalism.

Nihilism: Necessarily, for any $x s$, there is a $y$ composed of those $x s$ iff there is only one of the $x s .{ }^{7}$

On this view there are only "mereological simples" - objects without any proper parts. Thus no brains, bodies, atoms, rocks, etc.

It is an interesting question what an object has to be like in order to be a mereological simple, but I won't address that question here. ${ }^{8}$

Van Inwagen's own view is perhaps the third-ranked one on the market. The basic idea behind van Inwagen's thesis is that the only composite objects (objects made of two or more parts) are living organisms.

Van Inwagen's Proposed Answer (VIPA): Necessarily, for any $x_{s}$, there is a $y$ composed of those $x_{S}$ iff either (a)

${ }^{5}$ For defenses of Universalism see Lewis, On the Plurality of Worlds, esp. pp. 211-213; Sider, Four-Dimensionalism, esp. pp. 120-139; and Van Cleve, "Mereological Essentialism, Mereological Conjunctivism, and Identity Through Time," and "The Moon and Sixpence: A Defense of Mereological Universalism."

${ }^{6}$ For more objections to Universalism see van Inwagen, Material Beings, Section 8; and Markosian, "Restricted Composition."

7 For defenses of Nihilism see Unger, "I Do Not Exist" and "There Are No Ordinary Things;" and Dorr, "What We Disagree About When We Disagree About Ontology."

8 I do address this question in "Simples," where I defend a view according to which (roughly) physical mereological simples are objects that are spatially continuous. 
there is only one of the $x s$, or else (b) the activities of the $x s$ constitute a life. ${ }^{9}$

(The first condition of VIPA is to allow for the fact that each object automatically composes itself.) The idea behind VIPA is that in every case of composition involving two or more parts, those parts compose something in virtue of being such that their activities constitute a life. So on this view there are only simples and living things. Hence no atoms, rocks, tables, or stars. (And maybe no brains, depending on whether brains count as living things.)

There are several other less popular views that have been discussed in the literature. But here is what probably deserves to be called the least popular one of all. (I think I'm the only one who ever endorsed it in print, and even I no longer think it's true.)

Brutal Composition: (i) There is no true and informative answer to SCQ. (ii) Whenever some xs compose something, it is just a brute fact that they do so. ${ }^{10}$

I'll return later to the question of why Brutal Composition is so unpopular, because I think it is important. But for now I'll just note that many people apparently don't like the claim that compositional facts are brute facts.

In any case, here is the important thing to notice from our quick survey of answers to SCQ: every one of the leading views on the market (counting Brutal Composition as not among the leading views) has wildly counterintuitive consequences. It's mereological madness. So is there another way?

\section{Mereological Sanity}

As I mentioned at the beginning of this paper, I think the road to mereological sanity begins with first considering another mereological question that has not been discussed in the published literature on the mereology of physical objects. In a way this other question is simpler than SCQ, and more basic. Instead of asking about the multigrade relation of composition, this other

\footnotetext{
${ }^{9}$ For an explanation and extended defense of this view see van Inwagen, Material Beings.

10 For a defense of Brutal Composition see Markosian, "Brutal Composition."
} 
question asks about the two-place relation in terms of which composition is defined, namely, parthood. Here is the question I have in mind.

A Question About Parthood (QAP): Under what circumstances is one object a part of another object? ${ }^{11}$

(Despite the way I have worded QAP, I think it's clear that, just as with SCQ, what we really want in an answer to QAP is an account of what it is in virtue of which one object is a part of another.)

The proponents of the various answers to SCQ will have their own ways of answering QAP, some of which we will get to shortly. But first I want to discuss the answer to QAP that I think is the key to solving our mereological problems. Here it is.

The Subregion Theory of Parthood (STP): For any $x$ and for any $y, x$ is a part of $y$ iff the region occupied by $x$ is a subregion of the region occupied by $y .{ }^{12}$

I would say that of all the main answers to all the various questions concerning the mereology of physical objects, STP is probably the most intuitive. Only a complete mereological radical would deny that occupying a subregion of the region occupied by an object is a necessary condition for being a part of that object. ${ }^{13}$ In fact, I would go so far as to suggest that the claim that a part must occupy a subregion of the region occupied by the whole is a non-negotiable feature of our everyday conception of a physical object. And the idea that occupying a subregion is a sufficient condition for being a part has a great deal of intuitive appeal (even if it is susceptible to a certain objection, to be discussed below). It is of course a further question whether every object that is a part of another object is a part of that second object in virtue of occupying a subregion of the region occupied by the second object.

${ }^{11}$ QAP was one of the main topics of a paper called "Decomposition" that I presented at St. Andrews University and Rutgers University in 2005.

12 STP has been considered in one form or another by various philosophers. See for example Oppenheim and Putnam, "Unity of Science as a Working Hypothesis," Section 3.2; van Inwagen, Material Beings, Section 4; Casati and Varzi, Parts and Places, Chapter 2; Mellor, "Micro-Composition," Section 2; and Williams, "Working Parts: Reply to Mellor," Section 2.

${ }^{13}$ Raul Saucedo is such a radical. See his "Parthood and Location." 
But I think that giving an affirmative answer to this further question is wellsupported by commonsense intuitions (and is in fact more strongly supported by such intuitions than is any other view on the mereology of physical objects).

Despite its intuitive appeal, there is likely to be one main objection to STP. The objection is based on the possibility of colocation. Suppose it turns out that, according to the best physical theory, there are two completely different kinds of particle, alpha particles and beta particles. Suppose that alpha particles cannot interact causally in any way with beta particles. And suppose that both alpha and beta particles are unextended. Finally, suppose further that it is possible for an alpha particle and a beta particle to occupy the same pointsized region of space at the same time.

Now consider the following case. There are two point-sized simples, A and $\mathrm{B}$, in the same (point-sized) region, $\mathrm{R}$. A is an alpha particle, and B is a beta particle. There is also a composite object, $\mathrm{C}$, that occupies a larger region, $R^{*}$, which contains $R$ as a subregion. $A$ is a part of $C$ but $B$ is not. (Perhaps $C$ is a special kind of object that cannot have a beta particle as a part. Or perhaps the true answer to SCQ is some moderate answer, according to which there is a relation that some objects must stand in in order to compose a further object, and perhaps $B$ does not stand in that relation to the objects that compose $C$, or to any other objects. Alternatively, perhaps the true answer to SCQ is Universalism, which means that every collection of objects has a fusion, including numerous collections that include A but not B.) In any case, as far as $\mathrm{C}$ is concerned, B is "just passing through" - i.e., despite the fact that B occupies a point that is a part of the region occupied by $\mathrm{C}, \mathrm{B}$ itself is not a part of $\mathrm{C}$.

Here's why this case would be a counterexample to STP: the region occupied by $\mathrm{B}$ is a subregion of the region occupied by $\mathrm{C}$ (since the region occupied by $\mathrm{B}=$ the region occupied by $\mathrm{A}$, which itself is a part of $\mathrm{C}$ ), but, by hypothesis, $\mathrm{B}$ is not a part of $\mathrm{C}$.

And here is my reply to the objection. There are independent reasons for claiming that it's not possible for two physical objects to occupy the same place at the same time, and I am quite willing to make this claim. ${ }^{14}$ So I deny that the scenario described is possible.

14 But it's worth noting that the STPer does not have to say that colocation per se is impossible. For the view is consistent with there being two colocated objects, as long 
Before proceeding, I want to raise a further question that, although it does not appear to be mereological, is closely related to our several mereological questions. The question concerns the relation between a physical object and the region of space it occupies. Take you for example. You right now occupy a particular spatial location. So it makes sense to ask, In virtue of what do you occupy the region of space that you presently occupy? Here is our official formulation of the generalized version of this question.

A Question About Spatial Locations (QASL): In virtue of what does each physical object occupy the region of space that it occupies? ${ }^{15}$

It seems to me that there are very few plausible answers to QASL. It will not do, for example, to say that an object's spatial location is in virtue of its

as the two objects in question stand in all the same mereological relations to other objects. So what the STPer has to deny is the possibility of colocation without (what we can call) comereology. Since I happen to deny the possibility of colocation to begin with, I am also happy to deny the possibility of colocation without comereology; but other STPers may prefer to accept the possibility of colocation, while at the same time insisting that any two colocated objects must also be comereological.

Notice that the STPer who accepts the possibility of colocation, as long as the colocated objects are also comereologial, must reject the above example as impossible, since in the description of the example it was stipulated that A and B were colocated but not comereological. It is also worth pointing out that the STPer who accepts the possibility of colocation, as long as the relevant objects are also comereological, must in addition accept the possibility of two distinct objects, $x$ and $y$, such that $x$ is a part of $y$ and $y$ is a part of $x$. This will cause problems for the STPer if she wants to endorse the standard definition of 'proper part', according to which $x$ is a proper part of $y=\mathrm{df} x$ is a part of $y$ and $x$ is not identical to $y$. For in that case, the STPer will be forced to reject one of the most plausible principles of mereology, namely, the transitivity of proper parthood. (Because if she accepts that principle, then she will get the result that in a case of two colocated objects, $x$ and $y$, neither $x$ nor $y$ is identical to itself.) Thus the STPer who accepts the possibility of colocation (with comereology) should instead opt for some nonstandard definition of 'proper part', such as one according to which $x$ is a proper part of $y=\mathrm{df} x$ is a part of $y$ but $y$ is not a part of $x$. (This happens to be the definition of 'proper part' that I offered in "Simples.")

15 This question was also a main topic of the paper, "Decomposition," that I presented at St. Andrews and Rutgers in 2005. 
mass, or its color. What does seem plausible, however, is the idea that spatial location facts are all brute facts. Here is a formulation of this view.

Brutal Location (BL): (i) There is no true and informative answer to QASL. (ii) For any object, $x$, and region, $r$, if $x$ occupies $r$ then it is a brute fact that $x$ occupies $r$.

But I don't think that Brutal Location is the only plausible response to QASL. There is another, slightly less brutal approach. We could say that spatial occupation facts for mereological simples are indeed brutal, but that composite objects inherit their locations from the simples that compose them. Here is a way of stating this view. ${ }^{16}$

Moderately Brutal Location (MBL): For any object, $x$, and region, $r$, if $x$ is a mereological simple that occupies $r$, then it is a brute fact that $x$ occupies $r$; and if $x$ is a composite object that occupies $r$, then it does so in virtue of the fact that $r$ is the fusion of the regions occupied by the simples that compose $x .^{17}$

As it happens, I can't think of any other promising answers to QASL. ${ }^{18}$

16 Moderately Brutal Location is the answer to QASL that I defended in "Decomposition," but (as will be seen) I now endorse Brutal Location instead.

17 I take it that the proponent of Moderately Brutal Location will want to say that, strictly speaking, whenever some composite object, $x$, occupies some region, $r$, then it does so in virtue of the fact that $r$ is the fusion of the regions occupied by the simples that compose $x$, together with certain necessarily obtaining facts (such as the fact that Moderately Brutal Location is true). For I think we should say that, in general, it is often the case that the in-virtue-of basis for some derivative contingent fact involves not only the relevant contingent facts, but also certain necessarily obtaining facts that link those contingent facts with the derivative fact in question. But I also think that it's customary, when answering an In-virtue-of-what? question about a particular contingent fact, to let the relevant necessarily obtaining, linking facts remain implicit. For example, when we say that this shirt is red in virtue of being crimson, we typically have in mind that the shirt is red in virtue of the facts (a) that the shirt is crimson, and (b) that crimson is a shade of red. Similar remarks apply to Moderately Brutal Existence (see below).

18 Some philosophers will insist that Supersubstantivalism, according to which each object is identical to the region of space it occupies, provides a plausible answer to 
Meanwhile, here is one possible reason to prefer Brutal Location over Moderately Brutal Location: Moderately Brutal Location is inconsistent with the possibility of an object made of atomless gunk, that is, an object with proper parts such that each of its proper parts itself has proper parts. ${ }^{19}$ For Moderately Brutal Location entails that each physical object is composed of some simples. ${ }^{20}$

And here is another reason to prefer Brutal Location over Moderately Brutal Location: STP cannot be combined with Moderately Brutal Location, on pain of circularity. For suppose we say that some simple, $A$, is a part of some composite, $\mathrm{B}$, in virtue of the fact that the region occupied by $\mathrm{A}$ is a subregion of the region occupied by $\mathrm{B}$. Then if we endorse Moderately Brutal Location, we must also say that $B$ occupies the region it does partly in virtue of having $A$ as a part. So we will have to say that $A$ is a part of B partly in virtue of the fact that $A$ is a part of $B$.

What can the proponents of the different answers to SCQ say in response to QAP? Let's start with VIPA. Here is how I think its defenders must answer QAP.

The VIPA Theory of Parthood (VTP): For any objects, $x$ and $y, x$ is a part of $y$ iff either (i) $x$ is identical to $y$, or (ii)

QASL, namely, that for any object, $x$, and region, $r$, such that $x$ occupies $r, x$ occupies $r$ in virtue of being identical to $r$. For me, however, this view is not remotely plausible, on account of objections to Supersubstantivalism involving appeals to Leibniz's Law. For each object, it seems to me, typically has many properties that its location lacks (including various temporal and modal properties), and vice versa (including being occupied by a physical object, being such that it could exist in a world without any physical objects, and having its spatial location essentially).

19 Not that I personally can place much weight on this reason, since I happen to endorse a view about simples that also rules out the possibility of atomless gunk. See Markosian, "Simples."

20 There is a variation on Moderately Brutal Location that does not explicitly say that everything is composed of simples. According to this variation, if $x$ is a mereological simple that occupies $r$, then it is a brute fact that $x$ occupies $r$; and if $x$ is a composite object that occupies region $r$, then there are some ys such that the ys compose $x$ and $x$ occupies $r$ in virtue of the fact that $r$ is the fusion of the regions occupied by the $y$ s. But this view is also inconsistent with the possibility of atomless gunk, provided we assume (as I think we must) that there can be neither an infinite series of facts such that each one obtains in virtue of its successor, nor a circular series of such facts. 
there is a life, $L$, such that the activity of $y$ constitutes $L$ and $x$ is "caught up in" $L$ (i.e., there are some $z$ s such that the activities of the $z s$ also constitute $L$ and $x$ is among the $z s)$.

I have just a quick comment on The VIPA Theory of Parthood. There are various well known objections to VIPA (including, especially, the claims that it comes with an impoverished ontology and that it entails the possibility of ontological vagueness) and those objections will carry over to The VIPA Theory of Parthood. For most of us, this is reason enough to reject The VIPA Theory of Parthood.

What about Nihilists? Here is the answer to QAP that they must endorse.

The Nihilistic Theory of Parthood (NTP): For any $x$ and for any $y, x$ is a part of $y$ iff $x$ is identical to $y$.

Here's my quick comment on this view: The Nihilistic Theory of Parthood is a fine theory of parthood for a Nihilist, but it will not do for anyone else. I won't raise any objections against Nihilism here (apart from noting that the two main standard objections are that it comes with an impoverished ontology and that it seems to leave no room for conscious material beings like ourselves), but will instead just assume that it is not the correct answer to SCQ. And on this assumption, The Nihilistic Theory of Parthood is not the correct answer to QAP.

How about the advocate Brutal Composition? Given that he thinks compositional facts are brutal, and given the way composition is defined in terms of parthood, I think the proponent of Brutal Composition has no choice but to endorse the following theory of parthood.

Brutal Parthood (BP): (i) There is no true and informative answer to QAP. (ii) Whenever one object is a part of another object, this is just a brute fact about those two objects.

What about the Universalist and QAP? It looks like there are two main options. The first is for the Universalist to endorse STP. If she does so, then she will maintain that every pair of non-overlapping objects (for example) composes a third object, and that each member of the pair is a part of the third object in virtue of occupying a subregion of the region occupied by the third object. Moreover, given that STP cannot be combined with Moderately Brutal 
Location, on pain of circularity, the Universalist who opts for this combination will also have to either endorse Brutal Location or else come up with some alternative answer to QASL. (I will return to this combination of views below.)

Meanwhile, the second main option for the Universalist is to eschew STP and instead answer QAP with Brutal Parthood. If she does so, then the Universalist will presumably want to accept Moderately Brutal Location as the answer to QASL. (More below on this combination too.)

Here is one last question we can ask our different theorists.

A Question About Existence (QE): In the case of each physical object, $x$, that exists, in virtue of what is it the case that $x$ exists?

It seems to me that existence, like spatial location, has got to be either fundamental or else very close to being fundamental. That is, I take it that the following are the only two reasonable ways of answering QE.

Brutal Existence (BE): (i) There is no true and informative answer to QE. (ii) For any $x, x^{\prime}$ s instantiation of existence is a brute fact.

Moderately Brutal Existence (MBE): For any $x$, if $x$ is a mereological simple, then $x^{\prime}$ s instantiation of existence is a brute fact; and if $x$ is a composite, then $x^{\prime}$ s instantiation of existence obtains in virtue of (i) facts about the existence of the simples that compose $x$, and (ii) facts about the way those simples are arranged. ${ }^{21}$

21 Given what I said in Footnote 17 above, the proponent of Moderately Brutal Existence will want to say that certain necessarily obtaining facts are also included in the fundamental basis for the existence of any composite object. These will presumably include a fact about what is the true answer to SCQ. Thus, e.g., a proponent of VIPA will say that the existence of a composite object obtains in virtue of the existence and arrangement of its simple parts, together with the fact that VIPA is true. 
Given that the Nihilist does not believe there are any composite objects, and assuming I am right about Brutal Existence and Moderately Brutal Existence being the only live options, ${ }^{22}$ the Nihilist will naturally favor Brutal Existence.

The Universalist, on the other hand, will presumably opt for Moderately Brutal Existence, with the only relevant fact about how the $x s$ are arranged being that they do not overlap. That is, she will say that if $x$ is a simple, then its instantiation of existence is a brute fact, but that if $x$ is a composite, then its instantiation of existence is in virtue of the existence of all of $x^{\prime}$ s simple parts, together with their not overlapping.

Similarly for proponents of the various moderate answers to SCQ: They will presumably want to say that if $x$ is a simple, then its instantiation of existence is a brute fact, but that if $x$ is a composite, then its instantiation of existence is in virtue of the existence of all of its simple parts, together with their being arranged in the way that they are arranged (in such a way that their activities constitute a life, or whatever).

There is a general picture of the great chain of being that will be appealing to Universalists and those who endorse some moderate answer to SCQ (such as VIPA). On this picture, the facts that are most fundamental are facts about the existence and arrangement of the world's simples; and various other facts, including existence facts about the world's composites, will be derivative on those. ${ }^{23}$

There are reasons to like this general picture of the great chain of being. But here is an argument against it, and in favor of Brutal Existence over Moderately Brutal Existence. I take facts to be instantiations of universals, and I think you should too. For example, the fact that you are human consists in your instantiation of the property humanity. ${ }^{24}$ For every fact, there is a

22 Actually, the assumption that Brutal Existence and Moderately Brutal Existence are the only live options is false. The other live option is the answer to QE that would be endorsed by a proponent of Jonathan Schaffer's Priority Monism (see Schaffer, "Monism: The Priority of the Whole"), according to which (roughly) the most fundamental facts about the world are all facts about the single whole that is the cosmos. But I am ignoring Priority Monism in this paper, for no particularly good reason.

23 This is in effect the opposite of Schaffer's Priority Monism (see previous footnote).

24 It might be thought that we can do without instantiations. But a world without instantiations would be an impoverished world in which no object actually has any 
corresponding proposition. For example, for the above fact there is the proposition that you are human. ${ }^{25}$ Both the fact and the proposition can be modeled by an ordered set. (But neither the fact nor the proposition is identical to the ordered set.)

Now, here is what I take to be a true principle about the in virtue of relation. (Let ' $p\left(F_{n}\right)$ ' refer to the proposition that corresponds to fact $F_{n \text {.) }}$ )

IVO Entailment: For any facts, $F_{1}$ and $F_{2}-F_{n}$, if $F_{1}$ obtains in virtue of $F_{2}-F_{n}$, then the conjunction of $p\left(F_{2}\right)-p\left(F_{n}\right)$ logically entails $p\left(F_{1}\right)$.

For example, if I am in Washington in virtue of the facts that (i) I am in Bellingham, (ii) Bellingham is in Washington, and (iii) the located-in relation is transitive, then the conjunction of the propositions that I am in Bellingham, that Bellingham is in Washington, and that the located-in relation is transitive entails the proposition that I am in Washington.

Now consider some composite individual - my son Zane, for example. He exemplifies the property existence. In virtue of what could that be the case? If it's not brutal, then the most likely candidate is what Moderately Brutal Existence suggests: Zane exemplifies existence in virtue of the fact that all of the relevant simples exist and are arranged a certain way (so that they don't overlap, or are fastened together, or are such that their activities constitute a life, or whatever), together with the fact that such-and-such is the true answer to SCQ. But the conjunction of the proposition that those simples exist and are arranged the way they are with the proposition that the relevant answer to SCQ is true does not entail the singular proposition that Zane exists. (For one thing, you could have the same simples arranged in the same way without having Zane. And for another thing, no acceptable system of logic will contain a "name introduction" rule of inference.) The most that the relevant propositions about the simples and the answer to SCQ could entail with respect to Zane is the general proposition that someone with such-and-such properties exists. In other words, we cannot get any singular propositions about Zane from the relevant propositions about his simples and SCQ. All we

property. Such a world could have you, and humanity, and many other properties, like mallardicity. But you would not be related to any of the properties - not even humanity - in any special way.

25 Why not identify facts with true propositions, then? Because something has to make the true propositions true, and they cannot make themselves true. 
get are some general propositions about a thing with certain properties. More generally, I don't see how we can get any singular facts about some object, $x$, obtaining in virtue of a bunch of facts that are purely general with respect to $x$. If this is right, and assuming that there are singular existence facts, I think it follows that singular existence facts, including ones about composite objects, must be brute facts.

So that's my argument - "The Zane Argument" - for Brutal Existence over Moderately Brutal Existence. But I want to emphasize that I find Brutal Existence to be independently very plausible, and would endorse it even in the absence of such an argument. Perhaps this is because I was brought up on the idea that the way to specify a possible world in model theory is first to specify a domain of individuals that exist at the world, and then to specify a function telling us which individuals have which properties and which ones stand in which relations to one another. On this way of thinking, the domain the entire domain, that is, not just the domain of simples, or some other subset of the entire domain - comes first, and then the distribution of properties and relations comes after. Thus the picture of being that I like is very different from the "simples up" picture preferred by the Universalist and others.

Now I want to offer a heuristic device that I hope will make it easier to appreciate the answer to SCQ that I want to defend - the one that is based on STP, that is, and the one that will allow us to avoid the mereological madness we encountered above.

Suppose you get a new job, working for God. Your main responsibility is to write "composition reports," each of which details, for a given possible world, all of the cases in that world in which some objects compose a further object. You have an assistant - we'll call him Bentley - who can give you any information you request about a given world, with the important exception that Bentley is not able to give you any mereological information. (That's above his pay grade.)

So you're given your first assignment: World 64. It's pretty clear how you should proceed if Universalism is true: you should ask Bentley for a list of all the mereological simples in World 64 (hoping that this doesn't count as mereological information), and then you should calculate all of the different ways of combining those simples. You should do a similar thing if Nihilism is true, although in that case your job would be even easier, since only cases of a single simple would be cases in which composition occurs. It's also pretty 
clear how you should proceed if VIPA is true, and similar remarks apply to most moderate answers to SCQ.

Here's what you should do if Brutal Existence, Brutal Location, and STP are all true. Ask Bentley for a list of every single thing that exists, and request that the list show, for each existing object, the location of that object. Then ask Bentley, while he is at it, to check for every case in which a plurality of objects is such that the fusion of the regions occupied by those objects shows up itself as the region occupied by one of the individual objects on the list. That is, you will be asking Bentley to identify every case like that of the object $\mathrm{x}_{4}$ in the following example.

\begin{tabular}{|ll|}
\hline Object & Location \\
\hline & \\
$\mathrm{X}_{1}$ & $\mathrm{R}_{1}$ \\
$\mathrm{x}_{2}$ & $\mathrm{R}_{2}$ \\
$\mathrm{x}_{3}$ & $\mathrm{R}_{3}$ \\
$\mathrm{x}_{4}$ & $\mathrm{R}_{4}\left(=\right.$ the fusion of $\mathrm{R}_{1}$ and $\left.\mathrm{R}_{2}\right)$ \\
\hline
\end{tabular}

Every such case will be a case of composition; and there will be no other cases of composition. You can write your composition report accordingly.

Here is an official formulation of the view suggested by these considerations.

Regionalism: Necessarily, for any $x s$, there is a $y$ composed of those $x$ s iff there is a region, $r$, and an object, $z$, such that $r$ is the fusion of the regions occupied by the $x s$ and $z$ occupies $r .^{26}$

I'd like to emphasize that, heuristic devices aside, Regionalism is a fairly straightforward consequence of the conjunction of Brutal Existence, Brutal Location, and STP. And STP is the key to this entailment. To see why, suppose that Brutal Existence, Brutal Location, and STP are all true. Since we are trying to prove Regionalism, we need to show that two things are true of any $x s$ : (i)

26 Strictly speaking, in order to have a chance of being true Regionalism needs to be qualified so that it says "for any non-overlapping xs..." (A similar remark applies to VIPA and to various other answers to SCQ.) This is an artifact of the standard definition of 'the $x$ s compose $y$ '. In what follows I will ignore this point. 
that if there is an object occupying the fusion of the regions occupied by the $x_{s}$, then there is an object composed of the $x_{S}$; and (ii) that if there is an object composed of the $x s$, then there is an object occupying the fusion of the regions occupied by the $x s$.

The proof of (i) is simple, since it involves assuming not only Brutal Existence, Brutal Location, and STP but also that (regarding some randomly chosen $x s$ ) there is an object occupying the fusion of the regions occupied by the $x$ s. Call this object A. Given STP, we know that each one of the $x s$ is a part of $A$ (since from the fact that A occupies the fusion of the regions occupied by the $x s$ it follows that they all occupy subregions of the region occupied by A). And we also know that every part of A must overlap at least one of the xs, since (a) every part of A must occupy a subregion of the region A occupies (this follows from STP) and (b) the region occupied by A is (by hypothesis) the fusion of the regions occupied by the $x s$. Hence A is composed of the $x_{s}$. And so we know that there is an object composed of the $x s$.

The proof of (ii) is even simpler. First we assume Brutal Existence, Brutal Location, and STP. Then we also assume of some randomly chosen $x$ s that there is an object composed of those $x$ s. And what we need to show from these assumptions is that there is an object occupying the fusion of the regions occupied by the $x$ s. Call the object composed of the $x s$ A. It follows immediately from STP plus the fact that A is composed of the $x s$ that every one of the $x s$ occupies a subregion of the region occupied by A. But from the fact that the $x s$ compose A we also know that there is no part of $\mathrm{A}$ that fails to overlap at least one of the $x$ s. So we know that the region occupied by $\mathrm{A}$ is the fusion of the regions occupied by the $x s$, and hence that there is an object occupying the fusion of the regions occupied by the $x$ s.

It should be noted that this proof of Regionalism from Brutal Existence, Brutal Location, and STP is really only concerned with the "necessary-andsufficient-conditions" versions of the four theses, and does not succeed in showing that the "in-virtue-of" version of Regionalism must be true if the corresponding versions of the other three theses are true. (This is why, as astute readers will have noticed, the above argument for Regionalism from Brutal Existence, Brutal Location, and STP makes no appeal to either Brutal Existence or Brutal Location. But presumably the more complicated argument that is needed to prove the in-virtue-of version of Regionalism would need to invoke Brutal Existence and Brutal Location.) I don't know how to make up for this deficiency in the proof, but I do not think it makes the proof 
uninteresting. For if we have successfully shown that the "necessary-andsufficient-conditions" version of Regionalism must be true if the corresponding versions of the other three theses are true, then that is certainly an important result.

In any case, Regionalism has some important advantages over its rival answers to SCQ. One is that it is consistent with commonsense intuitions about when composition occurs. Another one is that it is not susceptible to counterexamples the way all the other answers to SCQ seem to be. A third advantage is that it does not go against the popular intuition that compositional facts involving physical objects cannot themselves be brute facts.

And a fourth advantage of Regionalism is that it is part of a general approach to mereology that includes STP, and that reduces the mereology of physical objects to the mereology of the spatial regions that they occupy. This is what I call The Spatial Approach to Mereology.

The Spatial Approach to Mereology (SAM): The mereological properties and relations of physical objects are determined by the mereological properties and relations of the spatial regions those objects occupy. ${ }^{27}$

SAM gives us a neat, coherent, and highly intuitive account of the mereology of physical objects. And, best of all, it rescues us from all the mereological madness. ${ }^{28}$

\footnotetext{
27 The kind of determination I have in mind is the kind that is associated with the in virtue of relation.

${ }^{28}$ Here is a potential added bonus of accepting SAM. The conjunction of STP, Brutal Existence, Brutal Location, and Regionalism seems to entail a particular answer to The General Composition Question (see van Inwagen, Material Beings, Section 4). For the relevant conjunction seems to entail that for any $x$ s and for any $y$, the $x s$ compose $y$ iff the $x s$ do not overlap and the fusion of the regions occupied by the $x s=$ the region occupied by $y$. (There is a corresponding in-virtue-of version that also seems to follow from - or at least fit nicely with - the conjunction of STP and friends.) I am grateful to Joshua T. Spencer for making this point in correspondence.
} 


\section{Objections}

Despite these important advantages of Regionalism as an answer to SCQ, there are likely to be some objections. One possible objection is that Regionalism does not really rescue us from the mereological madness, because it is merely consistent with commonsense intuitions about when composition occurs and when it doesn't, but does not actually entail that those commonsense intuitions are correct. For Regionalism is also consistent with the possibility that our intuitions about specific cases of composition are even more radically mistaken than Universalism says they are.

My reply is that part of what the objection says is true and part of it is false. The true part is that Regionalism is merely consistent with commonsense intuitions about when composition occurs, but does not actually entail that those intuitions are correct. The false part is the claim that it follows from this that Regionalism does not really rescue us from the mereological madness. For the madness does not consist in the fact that the other responses to SCQ fail to entail the correctness of our intuitions about when composition occurs; the madness consists in the fact that the other responses (except for Brutal Composition, that is) entail that our intuitions are radically mistaken. And since Regionalism does not have this entailment, it does indeed rescue us from the madness.

A second possible objection says that there is really no difference between Regionalism and the widely detested Brutal Composition. For, the objection will go, anyone who did not like Brutal Composition is not going to like Brutal Existence, on account of its inconsistency with the appealing (to some people) picture of the great chain of being, according to which it is facts about the existence and arrangement of the world's simples that are most fundamental, and not any facts about the existence of composites.

Here is my reply. Regionalism is clearly very different from Brutal Composition. To see why, just notice that according to Regionalism, whenever some $x s$ compose something, it is not a brute fact that they do so. For according to Regionalism, whenever some $x_{S}$ compose something, this is in virtue of some facts about the spatial locations of some of the world's objects. Thus Brutal Composition says that composition is always brutal, and Regionalism says that it never is.

Perhaps the objection will now take a different form. It might be said that Regionalism may be different from Brutal Composition, but that it is nevertheless "just as bad" as Brutal Composition. For it still has some 
mysterious and brutal facts that opponents of Brutal Composition will not like. It's just that the brutality has been shifted over to the categories of existence and location.

My reply is that however good or bad Brutal Composition is as an answer to SCQ, the package I am offering now, including Regionalism, is clearly superior. Here's why. Given the way composition is defined, namely, in terms of parthood, the proponent of Brutal Composition must, as suggested above, endorse Brutal Parthood as the answer to our Question About Parthood. So Brutal Composition necessarily involves two crucial kinds of mereological brutality, whereas Regionalism is part of a package (SAM) that involves no mereological brutality at all, but, instead, offers a very natural and intuitive picture according to which all the mereological relations among physical objects obtain in virtue of the spatial relations among those objects.

A fourth objection that is likely to be raised is that STP, the engine driving SAM, is circular. It attempts to define parthood in terms of spatial relations, but the crucial spatial relation involved is the subregion relation, which can only be understood as the parthood relation on regions of space.

Here's the beginning of my reply. Neither STP nor Regionalism says anything about how to define any mereological notion. They are all about the in virtue of relation, and which facts the mereological facts involving physical objects obtain in virtue of.

But if we started out wanting an account of what it is in virtue of which mereological relations among physical objects obtain, and we are told that they obtain in virtue of the mereological relations among regions of space, then we will naturally want to know what it is in virtue of which the mereological relations among those regions obtain. In other words, however plausible SAM might be as an account of the mereology of physical objects, it remains incomplete until we also have a theory about the mereology of spatial regions.

Here is my reply. It's true that SAM invites questions about the mereology of regions of space, and is in a sense incomplete without such a theory to accompany it. But luckily, such a theory is readily available. For we can very plausibly offer a "classical" mereology for regions of space, according to which (i) simple regions of space are all point-sized, and (ii) every collection of (non-overlapping) regions is such that there is a region composed of the members of that collection. My proposal, then, is to begin by answering the various questions about what it is in virtue of which a given region has a 
certain mereological property, or stands in a certain mereological relation to another region, in accordance with the classical picture of mereology, and then to answer all of the in-virtue-of-what? questions regarding the mereology of physical objects by appealing to spatial facts about those objects, as per SAM.

A further objection that is likely to be raised at this point is that there is something wrong with claiming (as I have now claimed) that one set of mereological principles governs one category of objects (physical objects), while another, completely different set of mereological principles governs a second category of objects (regions of space).

My reply is that there is nothing wrong with this, and that in fact there is something very right about it. For I would argue that one natural and fruitful way of thinking about the structure of the world is that mereology is part of what carves ontology, meaning that one crucial factor that can separate one ontological category from another is that the two categories are governed by different sets of mereological principles. ${ }^{29}$

Here is a final objection to Regionalism. If objects can have indeterminate spatial locations (as certain theories in quantum physics seem to suggest), then, according to Regionalism, it can be indeterminate whether one object is a part of another. More generally, if there can be objects with indeterminate spatial locations, then there can be failures of determinateness among mereological relations. ${ }^{30}$

One possible reply is that there is nothing wrong with indeterminate parthood, and indeterminate mereological relations in general, if objects can have indeterminate locations. In fact, the Regionalist could say, once you appreciate that mereological relations among physical objects are all determined by the spatial relations among the relevant objects, as SAM says, then this is precisely the result you should want. I.e., if there really are objects with indeterminate locations, then there must be some indeterminateness in mereological relations as well.

29 Another component of the idea that mereology carves ontology is the thesis that mereological relations cannot obtain among objects from different ontological categories. (So, for example, there cannot be a fusion of your body and the number 2.) The idea that mereology carves ontology is developed further in my unpublished work-in-progress, Things and Stuff.

30 Thanks to Ross Cameron for raising this objection in correspondence. 
Here is a second reply open to the Regionalist. The Regionalist could maintain that although it is possible for an object to have an indeterminate spatial location, it is not possible for there to be two objects, $x$ and $y$, such that it is indeterminate whether $x$ occupies a subregion of the region occupied by $y$. (And similarly with the other mereological relations.)

There is a third possible reply to the objects-with-indeterminate-spatiallocations objection (and it is the one that I personally happen to prefer). For those who are inclined toward Regionalism, but balk at the idea of indeterminate mereological relations, the third option is to say that it simply is not possible for an object to have an indeterminate spatial location. It may be difficult or even theoretically impossible for anyone to determine the spatial locations of some objects, according to this line of thought, but it remains necessarily true that every object must be such that it has a determinate spatial location. And there may in fact be independent reasons for saying this.

\section{Taking Stock}

Before concluding I would like to return to the question of why Brutal Composition is so unpopular. I think the main reason is that (as it turns out) it's implausible to many philosophers to say that it is just a brute fact that some $x s$ compose something. We tend to want there to be some other fact or facts in virtue of which these $x$ s compose a further object.

But more generally, I think philosophers tend to balk at any claim about something's being a brute fact. This means that any view that explicitly indicates where its bruteness is located is at a rhetorical disadvantage when competing with views that don't do that. But it is worth remembering that you have to have brute facts somewhere in your theory. ${ }^{31}$

Here, then, is a table summarizing some of the main packages of views we have surveyed that makes it clear, for each combination of views, where that package's brutality is located. (In the table there are two versions of Universalism, corresponding to the above two options for the Universalist when it comes to answering QAP.)

31 I am assuming that neither (i) having an infinite series of increasingly more fundamental facts, without a rock-bottom level, nor (ii) having circularity with respect to the in virtue of relation is a tenable option. 


\section{A Table of Some of the Main Mereological Packages}

\begin{tabular}{|l|l|l|l|l|}
\hline & SCQ & QAP & QASL & Existence \\
\hline Universalism1 & Universalism & BP & MBL & MBE \\
\hline Universalism2 & Universalism & STP & BL & MBE \\
\hline Nihilism & Nihilism & NTP & BL & BE \\
\hline VIPA & VIPA & VTP & MBL & MBE \\
\hline $\begin{array}{l}\text { Brutal } \\
\text { Composition }\end{array}$ & $\begin{array}{l}\text { Crutal } \\
\text { Composition }\end{array}$ & BP & MBL & MBE \\
\hline SAM & Regionalism & STP & BL & BE \\
\hline
\end{tabular}

I take it that Universalism 1 fits best with what real Universalists actually say. The standard Universalist will presumably want to endorse the picture of being according to which facts about the world's simples are among the most fundamental, and this will commit her to Moderately Brutal Existence and Moderately Brutal Location. But as we saw above, there is a good argument (namely, The Zane Argument, about singular existence facts) in favor of Brutal Existence over Moderately Brutal Existence. Moreover, since most Universalists have a strongly negative reaction to Brutal Composition, it is likely that most of them will have a similar reaction to Brutal Parthood. For this reason I think there is a hidden but significant tension in this first Universalist package.

Here is another consideration that for me weighs heavily against the Universalism1 package. According to this package, with its commitments to Moderately Brutal Existence and Moderately Brutal Location, some existence 
facts and some spatial location facts (namely, those involving simples) are brutal, while other existence facts and other spatial location facts (namely, those involving composites) are derivative. Meanwhile, according to this package, some mereological facts (namely, facts of the form " $x$ is a part of $y$ ") are brutal, while other mereological facts (namely, those of the form "there is a $y$ composed of the $x s^{\prime \prime}$ ) are derivative. This strikes me as undesirably messy and inelegant. It is much better to say, with SAM, that when it comes to physical objects, all existence facts and all location facts are brutal, and also that all mereological facts are derivative.

Meanwhile, Universalism2 has to include Moderately Brutal Existence rather than Brutal Existence because (as we have seen) the combination of Brutal Existence with STP and Brutal Location would entail Regionalism rather than Universalism. So the only differences between the Universalism2 package and SAM are (i) the extreme counterintuitiveness of Universalism, and (ii) the fact that Universalism 2 makes existence facts for composites derivative (so that Universalism2, like Universalism1, entails that some existence fact are brutal and others are not). Given this tradeoff, and taking into account The Zane Argument for Brutal Existence, it looks to me like SAM is a much better option than Universalism2.

In any case, the upshot is that there are pretty big problems with both Universalist packages.

Nihilism is the only other package in this table, aside from SAM, that includes Brutal Existence rather than Moderately Brutal Existence. So it is the only other package that does not run afoul of The Zane Argument. And it is no doubt a virtue of Nihilism that existence and location are the only things in this general vicinity that it takes to be brutal. But the Nihilist package of course requires Nihilism and The Nihilistic Theory of Parthood, both of which do violence to commonsense.

Meanwhile, VIPA is in a position almost as bad as Nihilism's when it comes to commonsense, and the VIPA package also runs afoul of The Zane Argument from singular existence facts for Brutal Existence.

The Brutal Composition package has certain advantages with respect to commonsense intuitions about specific cases of composition, but it also contains its unpopular claim that composition facts are brutal, together with the necessary corollary about parthood facts being likewise brutal. In addition, it too ends up on the wrong side of The Zane Argument for Brutal Existence over Moderately Brutal Existence. 
Meanwhile, it seems to me that SAM fares much better than any other view surveyed here. It has no implausible consequences regarding specific cases of composition (because, like Brutal Composition, it has no such consequences of any kind), and it is based on STP, the most intuitive and straightforward account of parthood on the market. In addition, SAM is the result of combining (a) this most natural thesis about parthood with (b) a view about existence that is supported by the argument from singular existence facts and (c) the corresponding view of spatial locations. Moreover, SAM is a much cleaner, more elegant package than, say, Universalism ${ }_{1}$, insofar as SAM allows us to say that all existence facts are uniformly brutal (rather than forcing us to say that some are brutal and some are not), and also that all mereological facts are uniformly derivative (rather than forcing us to say that mereological facts are a mixed bag of brutal and derivative facts). ${ }^{32}$

\section{References}

Casati, Roberto, and Varzi, Achille, Parts and Places (Cambridge, MA: The MIT Press, 1999).

Dorr, Cian, "What We Disagree About When We Disagree About Ontology," in Mark Kalderon (ed.), Fictionalist Approaches to Metaphysics (Oxford: Oxford University Press, 2005), pp. 234-286.

Lewis, David, On the Plurality of Worlds (Oxford: Basil Blackwell, 1986).

Markosian, Ned, “Brutal Composition," Philosophical Studies 92 (1998), pp. 211249.

32 I am grateful to Ross Cameron, Hud Hudson, Shieva Kleinschmidt, John Maier, Laurie Paul, Jonathan Schaffer, Theodore Sider, Joshua T. Spencer, Gabriel Uzquiano, Ryan Wasserman, Tobias Wilsch, an anonymous referee, and audiences at Oxford University and The Australian National University for helpful comments on earlier versions of this paper, and to audiences at St. Andrews University, Rutgers University, and the 2008 eidos Metaphysics Conference for comments on more distant ancestors of this paper. 
Markosian, Ned, "Restricted Composition," in T. Sider, J. Hawthorne, and D. Zimmerman (eds.), Contemporary Debates in Metaphysics (Oxford: Blackwell Publishing), pp. 341-364.

Markosian, Ned, "Simples," Australasian Journal of Philosophy 76 (1998), pp. 213-226.

Markosian, Ned, “What Are Physical Objects?" Philosophy and Phenomenological Research 61 (2000), pp. 375-395.

Mellor, D.H., “Micro-Composition,” Philosophy 83 (2008), pp. 65-80.

Oppenheim, Paul, and Putnam, Hilary, "Unity of Science as a Working Hypothesis," in Feigl, Herbert, Scriven, Michael, and Maxwell, Grover, Minnesota Studies in the Philosophy of Science, Volume II (Minneapolis: University of Minnesota Press, 1958); reprinted in Boyd, Richard, Gasper, Philip, and Trout, J.D. (eds.), The Philosophy of Science (Cambridge, MA: MIT Press, 1991).

Saucedo, Raul, "Parthood and Location," in Zimmerman, Dean (ed.), Oxford Studies in Metaphysics, Volume 5 (Oxford: Oxford University Press, forthcoming).

Schaffer, Jonathan, "Monism: The Priority of the Whole," The Philosophical Review (forthcoming).

Sider, Theodore, Four-Dimensionalism (Oxford: Oxford University Press, 2001).

Unger, Peter, "I Do Not Exist," in G.F. Macdonald (ed.), Perception and Identity: Essays Presented to A.J. Ayer with His Replies to Them (New York: Macmillan), pp. 235-251.

Unger, Peter, “There Are No Ordinary Things," Synthese 41 (1979), pp. 117154.

Van Cleve, James, "Mereological Essentialism, Mereological Conjunctivism, and Identity Through Time," in P.A. French, T.E. Uehling, Jr., and H.K. 
Wettstein (eds.), Midwest Studies in Philosophy Volume XI (Minneapolis: University of Minnesota Press, 1986), pp. 141-156.

Van Cleve, James, "The Moon and Sixpence: A Defense of Mereological Universalism," in T. Sider, J. Hawthorne, and D. Zimmerman (eds.), Contemporary Debates in Metaphysics (Oxford: Blackwell Publishing), pp. 321340.

Van Inwagen, Peter, Material Beings (Ithaca: Cornell University Press, 1990). 